Available online at www.sciencedirect.com

\title{
ScienceDirect
}

Journal of Hydrodynamics

2009, 21(6):868

DOI: $10.1016 / \mathrm{S} 1001-6058(08) 60226-7$

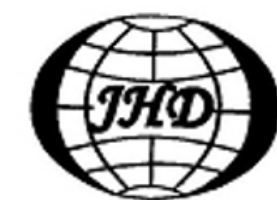

www.sciencedirect.com/

science/journal/10016058

ERRATUM

\section{ERRATUM TO "CHARACTERISTICS OF PRESSURE DROP AND CORRELATION OF FRICTION FACTORS FOR SINGLE-PHASE FLOW IN ROLLING HORIZONTAL PIPE"}

\section{[JOURNAL OF HYDRODYNAMICS, 2009, 21(5)]}

ZHANG Jin-hong, YAN Chang-qi, GAO Pu-zhen

College of Nuclear Science and Technology, Harbin Engineering University, Harbin 150001, China

\begin{tabular}{|c|c|}
\hline ARTICLE INFO & ABSTRACT \\
\hline $\begin{array}{l}\text { Article history: Received March 10, } 2008 \\
\text { Accepted: June 20, } 2008\end{array}$ & $\begin{array}{l}\text { This is the erratum to the article [zhang Jin-hong, Yan Chang-qi, Gao } \\
\text { Pu-zhen, Journal of Hydrodynamics, 2009, 21(5)]. The fig. } 5 \text { is corrected. }\end{array}$ \\
\hline
\end{tabular}

In ref. [1], fig.5 should be as follow:

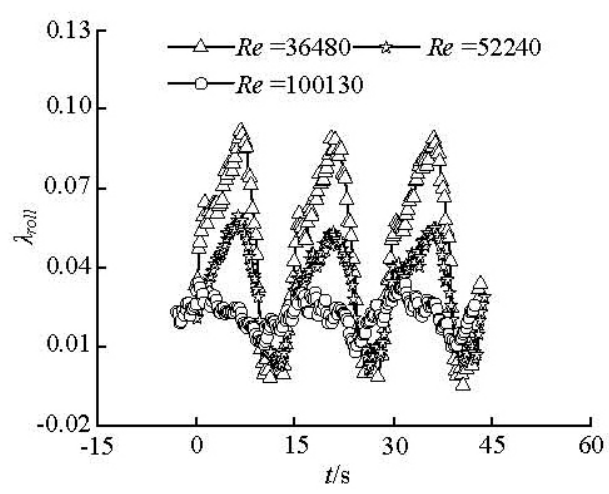

Fig.5 Variation of friction factor $\lambda_{\text {roll }}$ with the Reynolds number $\operatorname{Re}\left(D=34.5 \mathrm{~mm}, \theta_{m}=10^{\circ}, T=15 \mathrm{~s}\right)$

\section{References}

[1] ZHANG Jin-hong, YAN Chang-qi, Gao Pu-zhen. Journal of Hydrodynamics, 2009, 21(5).

DOI of original article: 10.1016/s1001-6058(08)60192-4.

E-mail address: jinhong126@sina.com 